\title{
6 A A Note on Editorial Method
}

WITH CERTAIN exceptions, we have changed the spelling and punctuation of the texts in this volume to conform to modern usage. The exceptions are the poetry and those works (such as Sewall's Diary) that are reprinted from widely used scholarly editions. We have not changed archaic forms of words where the change would affect sound: for example, divers has not become diverse; salvages has not become savages. We have edited the texts in this way because one important aim of this book is to recover inaccessible works for the modern reader. Many seventeenth-century sermons were transcribed by unknown hands from oral delivery, and such aspects of the original texts as italicization, capitalization, irregular spelling, sometimes even marginal scriptural citations, were not necessarily stipulated by the author. Moreover, we believe that faithfully preserving such features from the early editions would, in some cases, lend the texts an air of eccentricity that they did not have for contemporary readers. The editions upon which our texts are based are identified in each case. (The date given for each selection is the year of composition, not necessarily that of first publication.)

We have supplied annotation in the same spirit. Foreign phrases have been translated; some (by no means all) biblical paraphrases and citations have been identified; archaic words and references that are not immediately clear have been explained. We have kept the annotation at a minimum, however. Our aim is to remove stumbling blocks without burdening the reader with exhaustive commentary.

We indicate with ellipses those places where writing has been omitted. To avoid a text cluttered with endless dots, we do not always indicate small deletions (such as biblical references or Greek phrases that are translated by the author). In choosing what to include in the volume, we concentrated on works that are hard to come by outside the rare-book libraries; we do not supply long excerpts from those which are more readily available, such as Bradford's History. 
This book is best used in the company of the Oxford English Dictionary and the Authorized or the Geneva Bible. (Puritans used both biblical texts; citations have been given from the more familiar King James version.) Often, a minister quotes a fragment of scripture to illustrate or introduce a point, safely assuming that his auditors will instantly recall the rest of the passage. In such instances we usually give the remainder of the quotation in a note.

Our work has been cooperative from the start, much of it taking shape as we talked over how best to teach the literature of colonial New England and what kind of book would be most useful in the classroom. In the realization of our plans, there has been a division of labor: Andrew Delbanco is responsible for the Introduction and the selections and introductory materials in Parts I, III, and V; Alan Heimert for Parts II, IV, and VI and the Afterword. 